\title{
Regenerative Medicine Treatments for Androgenetic Alopecia
}

\author{
Venkataram Mysore $^{1}$ Sajin Alexander ${ }^{2}$ Suman Nepal ${ }^{3}$ Aniketh Venkataram ${ }^{1}$ \\ ${ }^{1}$ The Venkat Center for Skin ENT and Plastic Surgery, Bangalore, India \\ ${ }^{2}$ Department of Dermatology, Sony Memorial Hospital, Erumely, \\ Kottayam, Kerala, India \\ ${ }^{3}$ Avaram Skin Clinic, Kathmandu, Nepal \\ Address for correspondence Aniketh Venkataram, MBBS, MS, MCH, \\ The Venkat Center for Skin ENT and Plastic Surgery, India \\ (e-mail: anikethv@gmail.com). \\ Indian J Plast Surg 2021;54:514-520.
}

\begin{abstract}
Keywords

- regenerative medicine

- nanofat

- plateletrich plasma

- stem cells

- androgenetic alopecia

Regenerative medicine and the role of stem cells are being studied for applications in nearly every field of medicine. The pluripotent nature of stem cells underlies their vast potential for treatment of androgenic alopecia. Several advances in recent years have heightened interest in this field, chief among them are the evolution of simpler techniques to isolate regenerative elements and stems cells. These techniques are easy, outpatient procedures with immediate injection, often single session with harvest, and minimal manipulation (usually physical). This paper seeks to critically review the existing data and determine the current evidence and their role in practice.
\end{abstract}

\section{Introduction}

Regenerative medicine and the role of stem cells are being studied for applications in nearly every field of medicine. Hence, it was inevitable that they be viewed through the lens of hair loss treatment too.

The pluripotent nature of stem cells underlies their vast potential for treatment of androgenic alopecia (AGA). ${ }^{1}$ Availability of autologous tissue makes it more attractive to practitioners and patients. However, traditional methods of obtaining stem wells were complicated, usually involving culturing. This meant that they were often expensive and could not be done in a single stage.

Several advances in recent years have heightened interest in this field, chief among them are the evolution of simpler techniques to isolate regenerative elements and stems cells. These techniques are easy, outpatient procedures with immediate injection, often single session with harvest, and minimal manipulation (usually physical). This also reduces cost and eliminates regulatory issues with the use of stem cells. ${ }^{2}$ This has also led to awareness and publicity on social media, demand by the patients, resulting in their clinical use, and even premature commercial exploitation. This paper seeks to critically review the existing data and determine the current evidence and their role in practice.

\section{Stem Cells, Growth Factors and Pathophysiology of Hair Loss}

Management of alopecia involves modifications to two types of stem cells (SCs)-hair follicle stem cells (HFSCs), and dermal papilla cells (DPCs). In scarring alopecia, there is irreversible loss of these SCs. But in AGA and other nonscarring alopecias, these cells are preserved till late stage, which enables reversal., ${ }^{3,4}$ The primary event in AGA is miniaturization of the HF. In balding scalp, the number of HFSCs remains intact, but the number CD34 and CD200 positive progenitor cells, which proliferate actively markedly decreases. This suggests that balding scalp may either lack an activator or has an inhibitor of HF growth. ${ }^{5}$

HFSCs express marker include CD34, K15, K19, CD200, PHLDA1, and EPCAM/Ber-EP4. DPCs express alkaline received

May 25, 2021

accepted after revision

September 5, 2021

published online

December 13, 2021
DOI https://doi.org/ 10.1055/s-0041-1739257. ISSN 0970-0358.

\footnotetext{
(c) 2021. Association of Plastic Surgeons of India. All rights reserved This is an open access article published by Thieme under the terms of the Creative Commons Attribution-NonDerivative-NonCommercial-License, permitting copying and reproduction so long as the original work is given appropriate credit. Contents may not be used for commercial purposes, or adapted, remixed, transformed or built upon. (https://creativecommons.org/ licenses/by-nc-nd/4.0/)

Thieme Medical and Scientific Publishers Pvt. Ltd., A-12, 2nd Floor, Sector 2, Noida-201301 UP, India
} 
phosphatase, alphaSMA, laminin, fibronectin, and CD133. , $^{6}$ These markers are modified in disease states. CK15 and CD34 both are lower, especially in the frontal scalp in AGA. SCs in the bulge remain in the resting phase for the vast majority of their lives. They are influenced by the mesenchymal cells of the dermal papilla and appear to be key in hair growth signal transmission. Early techniques of SC treatment for AGA involved isolating these SCs, culturing them, and then reinjecting them.

SCs are aimed at regenerating HFs through various methods ${ }^{8-10}$ :

- Reversing pathological mechanisms.

- Regenerating mature follicles from their parts, especially bulge cells.

- Neogenesis of HFs in culture.

The main sources for stem cells include

- Bone marrow.

- Adipose tissue.

- Scalp tissue.

- Blood.

- Other tissues such as Wharton's jelly.

\section{Adipose Tissue-Derived Stem Cells}

Normally, HFs encompassed by subcutaneous fat cells and the dermis shape an interfollicular dermal macroenvironment, which is imperative for maintaining the best possible growth of bulge and follicle cells. ${ }^{11,12}$ Adipocytes emit BMP2 during the late catagen stage and early telogen stage, which supports the resting state of HFSCs in the niche, whereas emission of BMP2 is lessened toward the late telogen stage, which bolsters the activation of HFSCs. Adipocytes thus play a critical role in extending the anagen stage. ${ }^{12,13}$

Adipose tissue (AT) contains numerous cells including adipocytes, adipose-derived stem cells (ADSCs), endothelial cells, fibroblasts, mural cells, and leukocytes. ${ }^{14}$ The ADSCs have self-renewable capacity and display multilineage potential. The number of pluripotent cells contained in a cubic centimeter of adipose tissue is 100 to 1,000 times larger than the number of stem cells contained in bone marrow. ${ }^{15}$ ADSCs also secrete various growth factors which have been shown to promote hair growth. These growth factors include vascular endothelial growth factor (VEGF), hepatocyte growth factor (HGF), insulin-like growth factor-1 (IGF-1), platelet-derived growth factor (PDGF), keratinocyte growth factor (KGF), and fibroblast growth factor-1 and 2 (FGF-1, FGF-2) ${ }^{16-21}$

ADSC-derived proteins improve hair growth and protect human DPCs against cytotoxic injury caused by androgen and reactive oxygen species. Moreover, conditioned media of ADSC (ADSC-CM) induces the anagen phase, promotes hair growth in mice, and enhances the elongation of hair shafts in ex vivo human hair organ cultures. ADSC-CM promotes hair growth in vitro, ex vivo, and in vivo. ${ }^{22}$

Thus, there seems to be a reasonable hypothesis for the use of ADSCs for AGA, based on the physiology. The technique is a simple and safe outpatient procedure and is well- established in various other indications. Several different ways of harvesting and using adipose-derived cells have been described such as whole fat, nanofat, and stromal vascular fractions. Various commercial devices to extract them have been described, which are mentioned below.

\section{Stromal Vascular Fraction}

The stromal vascular fraction (SVF) refers to all the cellular elements of the adipose tissue, excluding adipocytes such as smooth muscle cells, endothelial cells, blood cells, stem cells, and extracellular matrix. ${ }^{23}$ The majority of activity of SVF is attributable to ADSCs, and there is continuous intercellular cross-talking and signaling between these cells. ${ }^{24}$

SVF can be obtained by two methods-chemical and mechanical. Chemical methods involve enzymatic digestion with collagenase, which is subsequently inactivated. The pool of mononuclear cells is then isolated through filtration and centrifugation. This chemical SVF can then be used to culture ADSCs. ${ }^{25}$ Mechanical methods use physical disruption such as shaking, vortexing, sonification, etc., followed by washing and filtration. They contain fragments of extracellular matrix along with the cells. ${ }^{26}$

Mechanical SVF, also referred to as nanofat, has found increasing popularity, as it is easier to perform, requires less equipment, can be done in one sitting along with the harvest, and does not require any regulatory approval

Several studies have been published using the different types of fat mentioned above-autologous whole fat ${ }^{24-27}$, SVF, nano fat, ${ }^{28,29}$ etc. $^{27-36}$ These have been tried in different types of alopecias such as traumatic scars, alopecia areata, scarring alopecias such as scleroderma, and also AGA.

ADSCs have been the most widely studied, most of which, however, are in small number of patients, of short duration of follow-up, and hence of low evidence quality. A number of commercial devices have become available for extraction of SVF. Early publications show some benefits with these devices. ${ }^{37,38}$ One of the better studies with a long follow-up period was by Kuka et al who tried adipose-derived regenerative cell (ADRC)-enriched autologous fat grafts using Kerastem Celution system in 71 patients (17 females and 54 males) with $\mathrm{AGA}^{34}$. An increase in terminal hair count was demonstrated at weeks $6,12,24$, and 52 weeks with maximum hair count seen at week 24 . An interesting study by Butt et al assessed the efficacy of SVF combined with platelet-rich plasma (PRP) in 11 AGA patients. Mean hair density increased by $51.6 \%$ in SVF-PRP group as compared to only $21.5 \%$ in PRP group. There was also significant improvement in the physician and patient assessment scores in the SVFPRP group. ${ }^{39}$ A similar study by Stevens et al also reported benefits with the combined therapy of SVF with PRP (platelet-rich stroma [PRS] $)^{40}$

Several studies are available for ADSC-CM using commercial ADSC-CM products called advanced adipose-derived stem cell protein extract (AAPE) (Prostemics Co, Ltd, Seoul, South Korea) by Fukuoka et al who studied 68 patients of male and female pattern hair loss (PHL) over 5 years in three published studies. ${ }^{41-44}$ ADSC-CM was found to be effective in 
inducing hair growth. However, the authors seem to have recruited different patients in each study, and hence the follow-up period was not long in any of the studies, which is a significant limitation of these studies.

ADSCs have also been found to have efficacy in other pathological alopecias like $\mathrm{AA}^{4{ }^{4-47}}$ The same has been reported in patients undergoing hair transplantation as well. ${ }^{47}$

In terms of evaluation, there is some evidence of improved outcomes with AT treatments. However, there was significant variation in the methods of preparation of ADSCs and fat from harvested AT. Till now, there is no universal protocol for fat grafting and the various methods of fat harvesting, processing, and reinjection can affect results which lead to difficulty in comparing results from various studies. Most of these studies had small sample size, variable control groups, and different durations, methodologies and outcome measures. No large controlled studies exist and the level of evidence is low. They also lacked long-term data of less than 6 months except the study by Kuka et al. Hence, it can be said that AT and ADSCs may represent a potential therapy for hair regeneration and physicians need to be aware of developments in this field. Hence, the modality cannot at this stage be recommended as a routine option for management of AGA and can only be tried as part of a scientific research.

\section{Follicle Derived Stem Cells and Hair Loss}

Current evidence has shown that in balding scalp, the number of HFSCs remains intact, whereas the number of more actively proliferating progenitor cells markedly decreases. $^{48}$ This suggests that balding scalp either lacks an activator or has an inhibitor of HF growth. The authors Ruiz all developed a new method to isolate human adult stem cells by mechanical centrifugation of punch biopsy from human HFs. The scalp biopsy samples were mechanically disaggregated by a special centrifuge (Rigenera technology) to obtain an extract. The extract was directly infiltrated into the scalp of patients and patients were followed-up for 2 months. There was an increase in hair density and hair count. ${ }^{8,49}$ However, these are the only two published studies on this topic, and it is too premature to make any recommendations on this limited data

\section{Platelet-Rich Plasma in Treatment of Hair Loss}

PRP treatment has been steadily gaining popularity as a treatment option for hair loss, mainly AGA, in both men and women. PRP is the autologous plasma with platelet concentration, 2-7 times more than the baseline after centrifugation. ${ }^{50,51}$ Graziani et al suggested that a PRP concentration 2.5 times the baseline is optimal and that concentrations above this level would be inhibitory in nature $^{52}$

The activation of platelet $\alpha$-granules releases more than 20 different growth factors and cytokines, which are important in promoting cell proliferation and differentiation as shown in the box below. ${ }^{53,54}$ These include PDGF, IGF-1, transforming growth factor (TGF), endothelial growth factor (EGF), basic fibroblast growth factor (b FGF), granulocytemacrophage colony-stimulating factor (GM-CSF), and hepatocyte growth factor (HGF).

These growth factors have several actions on the HF, which are not fully understood as yet. These include:

1. Upregulation of GFs like IGF-1, FGF-7, HGF, and VEGF within the DPCs, thereby lengthening the anagen phase. $^{55,56}$

2. EGF, TGF, and PDGF may upregulate the growth and differentiation of the bulge cells by GFs. ${ }^{56-58}$

3. Activation of $W n t / \beta$-catenin pathway, ${ }^{56,59,60}$ thereby promoting conversion from telogen to the anagen phase.

4. Activation of extracellular signal-regulated kinase (ERK) and protein kinase B (Akt) signaling that promotes cell survival and prevents apoptosis $56,60,61$

5. PRP may also work via other anti-inflammatory mechanisms, too, which are helpful in the treatment of alopecia areata $^{62,63}$

These actions have led to the use of PRP in a number of clinical situations. However, it is also true that some actions of different growth factors may be conflicting in different situations and hence needs to be interpreted carefully.

Published date on the use of PRP in AGA has been expanding over years ${ }^{53,64-77}$. Several studies of use of PRP in AGA have been published with varying results in improvement in hair count, hair diameter, patient satisfaction, etc.

A critical analysis of these studies shows one striking aspect: the lack of standardization and wide variability in every aspect of PRP preparation, administration, and assessment. There is variation in volume of blood, type and duration of spin, type of kit and activator used, frequency, duration and follow-up period, etc.

a) Volume of blood collected: As stated earlier, the platelet count in PRP should be at least 3 times the normal to be significant. This means that at least about 25 to $30 \mathrm{~mL}$ blood would need to be collected. However, volumes of blood collected for preparation of PRP by different authors have ranged from $3.5 \mathrm{~mL}$ to $478 \mathrm{~mL}$, all demonstrating beneficial outcome! Some studies have used lower volumes of blood up to $5 \mathrm{~mL}$, with a smaller yield ranging around 1 to 2 times the baseline platelet count. ${ }^{53,67,74}$ While higher volumes of blood have yielded higher platelet concentrates of 4 to 6 times the baseline, ${ }^{65,66,69,71}$ there are a few exceptions of lower yields with higher blood volumes ${ }^{70,75,76}$. Vice versa is also true, with one study showing higher concentrate from a lower volume. ${ }^{68}$

b) Single versus double spin: Various authors have used various methods of preparation which may involve double- or single-spin centrifugation. Studies with single-spin centrifugation yielded only 2 to 3 times the baseline platelet concentrates even with higher volumes of blood collected. ${ }^{75,76}$ Double-spin methods have generally yielded higher platelet concentrates with less amount of whole blood drawn as compared 
to single spin $^{34}$ and hence may yield better outcome. ${ }^{78}$ There is inconsistency in the use of centrifugation force expressed as "rpm," rotations per minute and "g," relative centrifugal force, in different studies. ${ }^{79}$ Use of RPM can often be misleading, as it varies with the machine used and depends on the radius of the machine which makes replicating the findings of these studies difficult.

c) Methodology: Methods of outcome assessment in different studies have varied widely, making the interpretation difficult. Global photographic assessment was found to be the most common method of evaluation of hair growth. While this was done every session by some, ${ }^{80}$ others took photographs only at baseline and at 3- or 6-month intervals. ${ }^{81-83}$ Only few studies used dermoscopy, trichogram, and hair count for assessment of improvement. ${ }^{65,75,80}$ Further, these studies lacked adequate data on the photographic techniques used to reproduce the precise conditions in subsequent sessions. ${ }^{65,82,84}$ Only few studies have used special methods such as semipermanent tattoos, fixed stamps, and easy to remember landmarks to avoid the above variabilities. ${ }^{75,80,81,85}$

d) Number of sessions, duration of treatment and followup: There has been no uniformity in the number of session and interval between the sessions. Most studies used 3 sessions at monthly intervals. One of the most important yardsticks for any treatment of AGA is the duration of treatment and follow-up period. Majority assess the outcome by the end of the study ${ }^{81,84,86}$ which range from 3 to 6 months, depending on the number of treatment sessions. This can lead to premature conjecturing as changes and effects may be delayed. Follow-up assessment of outcome a few months after cessation of therapy is available only in few studies. ${ }^{75,82,83,85}$ Duration of follow-up is short, less than 1 year in most studies.

e) Type of kits: The initial PRP studies used preparation of PRP without any kit. Subsequent studies have used commercial PRP systems, which facilitate the preparation of PRP in a reproducible manner with a smaller volume of drawn blood. They use different activators and gels to aid separation of different fractions of blood. Assessment of these kits is difficult as they differ markedly in their ability to collect and concentrate platelets as well as in the method and time of centrifugation. $^{7}$

f) Placebo Component in PRP: PRP as a treatment has a strong placebo component. Use of one's own blood is an impressive concept on the impressionable mind of an AGA patient, looking desperately for a magical cure! Puig et al in their double-blinded placebo controlled study showed that PRP treatment showed no statistically significant improvement when compared with placebo saline injections. ${ }^{84}$ They concluded that PRP might have a strong placebo effect due to reporting of improvement of hair loss and texture by the study subjects as well as the placebo group. Another study by Ayatollahi et al showed no favorable results at the end of 5 sessions. ${ }^{81}$ An important feature, which explains its popularity, is that PRP has been founded to be relatively free from side effects, except minor side effects such as pain, discomfort, or mild scalp pruritus. ${ }^{50,85-88}$

Thus, it is obvious that a proper assessment of different studies is fraught with difficulty. While the above stated limitations are significant and relevant, it cannot be denied that there are multiple published studies that document efficacy of PRP and provide some evidence supporting PRP therapy in AGA with significant increase in number of hairs per $\mathrm{cm}^{2}$ with minimal to no adverse effects. ${ }^{89}$

A study by Schiavone et al on 64 patients with AGA treated with PRP showed some form of improvement in $97.5 \%$ of the patients. This included increase in hair thickness as well as hair density. They observed no significant difference clinically based on the gender or age group and concluded that PRP treatment was useful in both male and female PHL. ${ }^{82}$

Gupta et al performed a meta-analytic study which concluded that PRP could be used to improve hair restoration parameters (e.g., hair density) as a monotherapy or as an adjunct therapy. ${ }^{88}$ PRP has been shown to work even in patients who did not respond to topical minoxidil. ${ }^{80} \mathrm{~A}$ welldesigned randomized double-blinded placebo control study from India published recently (2020) on 80 patients with AGA compared the efficacy of different modalities in four groups (topical minoxidil only, PRP with minoxidil, normal saline [NS], and PRP only) in the treatment of AGA. The study found that the combination therapy of PRP with minoxidil was superior to all the other modalities. An interesting finding was that PRP as monotherapy was found to be superior to topical minoxidil in terms of hair density increase and patient satisfaction ${ }^{85}$ Similar results have been noticed in studies by Verma et al and Vats et al. ${ }^{86,89}$

Thus, the above review shows that literature on efficacy, preparation, administration, and treatment regimens are conflicting, and several questions still need to be answered. Further, high-quality controlled studies are required to accurately predict its long-term efficacy. It is significant that these questions persist despite PRP being available for nearly 5 years in the field of hair loss. It is significant to note that the European guidelines for $\mathrm{AGA}^{7,90}$ classified the evidence available as level 3 (studies grade $B$ evidence or studies with mainly consistent results grade $C$ evidence), and stated efficacy to improve or prevent hair loss as doubtful. The guidelines concluded that "there is no standardized technique for performing PRP to permit objective evaluation of its effects on AGA. We cannot make a recommendation for or against treatment of AGA with PRP at the present time The impact of PRP treatment on quality of life of the patients should be further investigated." In the authors' opinion, there is a void in the management of AGA between drug therapy and surgical therapy and PRP has sought to fill this void. However, there is a need to answer the following requirements, if PRP has to establish its position as a routine effective option: 
1. Standardized method of preparation with agreement on the minimum level of platelet count needed and identification of precise growth factors and their levels in the PRP.

2. Standardized frequency and duration of administration.

3. Studies on long term efficacy over 3 to 5 years.

The precise role of PRP, till then, will continue to be debated.

\section{Summary}

Regenerative treatments in management of hair loss has attracted great attention, both of doctors and lay public. However, the evidence shows that the potential and promise are yet to be met. Till standardization is achieved, controlled trials establish the evidence, and long-term data available, their routine use in clinical management is debatable. Evidence-based medicine demands that physicians adapt a questioning attitude and adhere to strict protocols while adapting such treatments. Below guidelines ${ }^{91}$ are recommended whenever physicians use such treatments:

1. Use such treatments only when standard treatments fail.

2. Full explanation should be provided to the patients about all aspects of the treatment and available evidence, specifically mentioning that adequate evidence is not yet available for the treatment, as part of informed consent.

3. Proper documentation about efficacy and safety should be ensured.

4. Cost of such treatments should be reasonable.

5. There should be no advertisements for such treatments.

Conflict of Interest

None.

\section{References}

1 Owczarczyk-Saczonek A, Krajewska-Włodarczyk M, Kruszewska $A$, et al. Therapeutic potential of stem cells in follicle regeneration. Stem Cells Int 2018;2018:1049641

2 Coelho MB, Cabral JM, Karp JM. Intraoperative stem cell therapy. Annu Rev Biomed Eng 2012;14:325-349

3 Ohyama M, Terunuma A, Tock CL, et al. Characterization and isolation of stem cell-enriched human hair follicle bulge cells. J Clin Invest 2006;116(01):249-260

4 Mohammadi P, Youssef KK, Abbasalizadeh S, Baharvand H, Aghdami N. Human hair reconstruction: close, but yet so far. Stem Cells Dev 2016;25(23):1767-1779

5 Garza LA, Yang CC, Zhao T, et al. Bald scalp in men with androgenetic alopecia retains hair follicle stem cells but lacks CD200-rich and CD34-positive hair follicle progenitor cells. J Clin Invest 2011; 121(02):613-622

6 Purba TS, Haslam IS, Poblet E, et al. Human epithelial hair follicle stem cells and their progeny: current state of knowledge, the widening gap in translational research and future challenges. BioEssays 2014;36(05):513-525

7 Inoue K, Aoi N, Sato T, et al. Differential expression of stem-cellassociated markers in human hair follicle epithelial cells. Lab Invest 2009;89(08):844-856

8 Gentile P, Scioli MG, Bielli A, Orlandi A, Cervelli V. Stem cells from human hair follicles: first mechanical isolation for immediate autologous clinical use in androgenetic alopecia and hair loss. Stem Cell Investig 2017;4:58

9 Asakawa K, Toyoshima KE, Ishibashi N, et al. Hair organ regeneration via the bioengineered hair follicular unit transplantation. Sci Rep 2012;2:424

10 Balañá ME, Charreau HE, Leirós GJ. Epidermal stem cells and skin tissue engineering in hair follicle regeneration. World J Stem Cells 2015;7(04):711-727

11 Zhang P, Kling RE, Ravuri SK, et al. A review of adipocyte lineage cells and dermal papilla cells in hair follicle regeneration. J Tissue Eng 2014;5:2041731414556850

12 Festa E, Fretz J, Berry R, et al. Adipocyte lineage cells contribute to the skin stem cell niche to drive hair cycling. Cell 2011;146(05): 761-771

13 Yi R. Concise review: mechanisms of quiescent hair follicle stem cell regulation. Stem Cells 2017;35(12):2323-2330

14 Eto H, Suga H, Matsumoto D, et al. Characterization of structure and cellular components of aspirated and excised adipose tissue. Plast Reconstr Surg 2009;124(04):1087-1097

15 Moseley TA, Zhu M, Hedrick MH. Adipose-derived stem and progenitor cells as fillers in plastic and reconstructive surgery. Plast Reconstr Surg 2006;118(03, Suppl):121S-128S

16 Yano K, Brown LF, Detmar M. Control of hair growth and follicle size by VEGF-mediated angiogenesis. J Clin Invest 2001;107(04): 409-417

17 Jindo T, Tsuboi R, Takamori K, Ogawa H. Local injection of hepatocyte growth factor/scatter factor (HGF/SF) alters cyclic growth of murine hair follicles. J Invest Dermatol 1998;110 (04):338-342

18 Tomita Y, Akiyama M, Shimizu H. PDGF isoforms induce and maintain anagen phase of murine hair follicles. J Dermatol Sci 2006;43(02):105-115

19 Weger N, Schlake T. Igf-I signalling controls the hair growth cycle and the differentiation of hair shafts. J Invest Dermatol 2005;125 (05):873-882

20 Danilenko DM, Ring BD, Yanagihara D, et al. Keratinocyte growth factor is an important endogenous mediator of hair follicle growth, development, and differentiation. Normalization of the nu/nu follicular differentiation defect and amelioration of chemotherapy-induced alopecia. Am J Pathol 1995;147(01): 145-154

21 Lin WH, Xiang LJ, Shi HX, et al. Fibroblast growth factors stimulate hair growth through $\beta$-catenin and Shh expression in C57BL/6 mice. BioMed Res Int 2015;2015:730139

22 Won CH, Park GH, Wu X, et al. The basic mechanism of hair growth stimulation by adipose-derived stem cells and their secretory factors. Curr Stem Cell Res Ther 2017;12(07):535-543

23 Alexander RW. Understanding adipose-derived stromal vascular fraction (SVF) cell biology in reconstructive and regenerative applications on the basis of mononucleated cell components. Journal of Prolotherapy 2013;10:15-29

24 Banyard DA, Sarantopoulos CN, Borovikova AA, et al. Phenotypic analysis of stromal vascular fraction after mechanical shear reveals stress-induced progenitor populations. Plast Reconstr Surg 2016;138(02):237e-247e

25 Oberbauer E, Steffenhagen C, Wurzer C, Gabriel C, Redl H, Wolbank S. Enzymatic and non-enzymatic isolation systems for adipose tissue-derived cells: current state of the art. Cell Regen (Lond) 2015;4:7

26 van Dongen JA, Stevens HP, Harmsen MC, van der Lei B. Mechanical micronization of lipoaspirates: squeeze and emulsification techniques. Plast Reconstr Surg 2017;139(06):1369e-1370e

27 Nilforoushzadeh MA, Lotfi E, Heidari-Kharaji M, Torkamaniha E, Hanifnia AR. Autologous whole fat injection stimulates hair growth in resistant androgenetic alopecia: report of nine cases. J Cosmet Dermatol 2020 ( e-pub ahead of print). Doi: 10.1111/ jocd. 13907 
28 Tedesco M. Adipose tissue transplant in recurrent folliculitis decalvans. Int J Immunopathol Pharmacol 2018;32:20587384 18814688

29 Dini M, Mori A, Quattrini Li A. Eyebrow regrowth in patient with atrophic scarring alopecia treated with an autologous fat graft. Dermatol Surg 2014;40(08):926-928

30 Nilforoushzadeh MA, Lotfi E, Heidari-Kharaji M. Autologous adipose transplantation an effective method to treat alopecia after trauma: a case report. Clin Cosmet Investig Dermatol 2019; 12:647-651

31 Cho SB, Roh MR, Chung KY. Recovery of scleroderma-induced atrophic alopecia by autologous fat transplantation. Dermatol Surg 2010;36(12):2061-2063

32 Vestita M, Filoni A, Bonamonte D, Elia R, Giudice G. Abstract: The Use of Nanofat in Androgenic Alopecia. a Prospective Blinded Study. Plast Reconstr Surg Glob Open 2017;5:90

33 Gentile P. Autologous cellular method using micrografts of human adipose tissue derived follicle stem cells in androgenic alopecia. Int J Mol Sci 2019;20(14):3446

34 Kuka G, Epstein J, Aronowitz J, et al. Cell enriched autologous fat grafts to follicular niche improves hair regrowth in early androgenetic alopecia. Aesthet Surg J 2020;40(06):NP328-NP339

35 Tak YJ, Lee SY, Cho AR, Kim YS. A randomized, double-blind, vehicle-controlled clinical study of hair regeneration using adipose-derived stem cell constituent extract in androgenetic alopecia. Stem Cells Transl Med 2020;9(08):839-849

36 Ozturk P, Bekerecioglu M. The effect of stromal vascular fraction for patients with androgenetic alopecia. J Turk Acad Dermatol 2020;14:107-111

37 Lee YI, Kim J, Kim J, Park S, Lee JH. The effect of conditioned media from human adipocyte-derived mesenchymal stem cells on androgenetic alopecia after nonablative fractional laser treatment. Dermatol Surg 2020;46(12):1698-1704

38 Narita K, Fukuoka H, Sekiyama T, Suga H, Harii K. Sequential scalp assessment in hair regeneration therapy using an adipose-derived stem cell-conditioned medium. Dermatol Surg 2020;46 (06):819-825

39 Butt G, Hussain I, Ahmad FJ, Choudhery MS. Stromal vascular fraction-enriched platelet-rich plasma therapy reverses the effects of androgenetic alopecia. J Cosmet Dermatol 2020;19 (05):1078-1085

40 Stevens HP, Donners S, de Bruijn J. Introducing platelet-rich stroma: platelet-rich plasma (PRP) and stromal vascular fraction (SVF) combined for the treatment of androgenetic alopecia. Aesthet Surg J 2018;38(08):811-822

41 Shin H, Ryu HH, Kwon O, Park BS, Jo SJ. Clinical use of conditioned media of adipose tissue-derived stem cells in female pattern hair loss: a retrospective case series study. Int J Dermatol 2015;54(06): 730-735

42 Fukuoka H, Suga H, Narita K, Watanabe R, Shintani S. The latest advance in hair regeneration therapy using proteins secreted by adipose-derived stem cells. Am J Cosmet Surg 2012;29:273-282

43 Fukuoka H, Suga H. Hair regeneration treatment using adiposederived stem cell conditioned medium: follow-up with trichograms. Eplasty 2015;15:e10

44 Fukuoka H, Narita K, Suga H. Hair regeneration therapy: application of adipose-derived stem cells. Curr Stem Cell Res Ther 2017; 12(07):531-534

45 Perez-Meza D, Ziering C, Sforza M, Krishnan G, Ball E, Daniels E. Hair follicle growth by stromal vascular fraction-enhanced adipose transplantation in baldness. Stem Cells Cloning 2017;10:1-10

46 Anderi R, Makdissy N, Azar A, Rizk F, Hamade A. Cellular therapy with human autologous adipose-derived adult cells of stromal vascular fraction for alopecia areata. Stem Cell Res Ther 2018;9 (01):141

47 Zanzottera F, Lavezzari E, Trovato L, Icardi A, Graziano A. adipose derived stem cells and growth factors applied on hair transplan- tation. follow-up of clinical outcome. Journal of Cosmetics Dermatological Sciences and Applications 2014;4:268-274

48 Ruiz RG, Rosell JMC, Ceccarelli G, et al. Progenitor-cell-enriched micrografts as a novel option for the management of androgenetic alopecia. J Cell Physiol 2020;235(05):4587-4593

49 Wu PI, Diaz R, Borg-Stein J. Platelet-rich plasma. Phys Med Rehabil Clin N Am 2016;27(04):825-853

50 Stevens J, Khetarpal S. Platelet-rich plasma for androgenetic alopecia: A review of the literature and proposed treatment protocol. Int J Womens Dermatol 2018;5(01):46-51. Published 2018 Sep 21

51 Marx RE. Platelet-rich plasma (PRP): what is PRP and what is not PRP? Implant Dent 2001;10(04):225-228

52 Graziani F, Ivanovski S, Cei S, Ducci F, Tonetti M, Gabriele M. The in vitro effect of different PRP concentrations on osteoblasts and fibroblasts. Clin Oral Implants Res 2006;17(02):212-219

53 Amable PR, Carias RB, Teixeira MV, et al. Platelet-rich plasma preparation for regenerative medicine: optimization and quantification of cytokines and growth factors. Stem Cell Res Ther 2013; 4(03):67

54 Trink A, Sorbellini E, Bezzola P, et al. A randomized, double-blind, placebo- and active-controlled, half-head study to evaluate the effects of platelet-rich plasma on alopecia areata. Br J Dermatol 2013;169(03):690-694

55 Jain R, De-Eknamkul W. Potential targets in the discovery of new hair growth promoters for androgenic alopecia. Expert Opin Ther Targets 2014;18(07):787-806

56 Alves R, Grimalt R. A review of platelet-rich plasma: history, biology, mechanism of action, and classification. Skin Appendage Disord 2018;4(01):18-24

57 Akiyama M, Smith LT, Holbrook KA. Growth factor and growth factor receptor localization in the hair follicle bulge and associated tissue in human fetus. J Invest Dermatol 1996;106(03): 391-396

58 Takikawa M, Nakamura S, Nakamura S, et al. Enhanced effect of platelet-rich plasma containing a new carrier on hair growth. Dermatol Surg 2011;37(12):1721-1729

59 Myung PS, Takeo M, Ito M, Atit RP. Epithelial Wnt ligand secretion is required for adult hair follicle growth and regeneration. J Invest Dermatol 2013;133(01):31-41

60 Gupta AK, Carviel J. A mechanistic model of platelet-rich plasma treatment for androgenetic alopecia. Dermatol Surg 2016;42(12): 1335-1339

61 Li ZJ, Choi HI, Choi DK, et al. Autologous platelet-rich plasma: a potential therapeutic tool for promoting hair growth. Dermatol Surg 2012;38(7 Pt 1):1040-1046

62 Gupta S, Bisht PB, Kannan C. Alopecia totalis successfully treated with modified platelet-rich plasma therapy in a patient recalcitrant to traditional treatment modalities. Clin Dermatol Rev 2021;5:120-122

63 Almohanna HM, Ahmed AA, Griggs JW, Tosti A. Platelet-rich plasma in the treatment of alopecia areata: a review. J Investig Dermatol Symp Proc 2020;20(01):S45-S49

64 Mazzocca AD, McCarthy MB, Chowaniec DM, et al. Platelet-rich plasma differs according to preparation method and human variability. J Bone Joint Surg Am 2012;94(04):308-316

65 Uebel CO, da Silva JB, Cantarelli D, Martins P. The role of platelet plasma growth factors in male pattern baldness surgery. Plast Reconstr Surg 2006;118(06):1458-1466

66 Takikawa M, Nakamura S, Nakamura S, et al. Enhanced effect of platelet-rich plasma containing a new carrier on hair growth. Dermatol Surg 2011;37:1721-1729

67 Perez AG, Lana JF, Rodrigues AA, Luzo AC, Belangero WD, Santana $\mathrm{MH}$. Relevant aspects of centrifugation step in the preparation of platelet-rich plasma. ISRN Hematol 2014;2014:176060

68 Landesberg R, Roy M, Glickman RS. Quantification of growth factor levels using a simplified method of platelet-rich plasma 
gel preparation. J Oral Maxillofac Surg 2000;58(03):297-300, discussion 300-301

69 Jo CH, Roh YH, Kim JE, Shin S, Yoon KS. Optimizing platelet-rich plasma gel formation by varying time and gravitational forces during centrifugation. J Oral Implantol 2013;39(05):525-532

70 Bausset O, Giraudo L, Veran J, et al. Formulation and storage of platelet-rich plasma homemade product. Biores Open Access 2012;1(03):115-123

71 Tamimi FM, Montalvo S, Tresguerres I, Blanco Jerez L. A comparative study of 2 methods for obtaining platelet-rich plasma. J Oral Maxillofac Surg 2007;65(06):1084-1093

72 Araki J, Jona M, Eto H, et al. Optimized preparation method of platelet-concentrated plasma and noncoagulating platelet-derived factor concentrates: maximization of platelet concentration and removal of fibrinogen. Tissue Eng Part C Methods 2012;18 (03):176-185

73 Kececi Y, Ozsu S, Bilgir O. A cost-effective method for obtaining standard platelet-rich plasma. Wounds 2014;26(08):232-238

74 Anitua E, Aguirre JJ, Algorta J, et al. Effectiveness of autologous preparation rich in growth factors for the treatment of chronic cutaneous ulcers. J Biomed Mater Res B Appl Biomater 2008;84 (02):415-421

75 Cervelli V, Garcovich S, Bielli A, et al. The effect of autologous activated platelet rich plasma (AA-PRP) injection on pattern hair loss: clinical and histomorphometric evaluation. BioMed Res Int 2014;2014:760709

76 Anitua E, Prado R, Sánchez M, Orive G. Platelet-rich plasma: preparation and formulation. Oper Tech Orthop 2012;22:25-32

77 Kahn RA, Cossette I, Friedman LI. Optimum centrifugation conditions for the preparation of platelet and plasma products. Transfusion 1976;16(02):162-165

78 El-Husseiny RM, Saleh HM, Moustafa AA, Salem SA. Comparison between single- versus double-spin prepared platelet-rich plasma injection in treatment of female pattern hair loss: clinical effect and relation to vascular endothelial growth factor. Arch Dermatol Res 2021;313(07):557-566

79 Mysore VChapter 89. Platelet-rich plasma therapy. In: ACSI (I) Textbook of Cutaneous and Aesthetic Surgery. 2nd ed. New Delhi: Jaypee Brothers Medical Publishers(P) Ltd; 2017:913-924
80 Sharma VK, Bhari N, Patra S, Parihar AS. Platelet-rich plasma therapy for androgenetic alopecia. Indian J Dermatol 2019;64 (05):417-419

81 Ayatollahi A, Hosseini H, Shahdi M, et al. Platelet-rich Plasma by single spin process in male pattern androgenetic alopecia: is it an effective treatment? Indian Dermatol Online J 2017;8(06):460-464

82 Schiavone G, Raskovic D, Greco J, Abeni D. Platelet-rich plasma for androgenetic alopecia: a pilot study. Dermatol Surg 2014;40(09): 1010-1019

83 Shah KB, Shah AN, Solanki RB, Raval RC. A comparative study of microneedling with platelet-rich plasma plus topical minoxidil (5\%) and topical minoxidil (5\%) alone in androgenetic alopecia. Int J Trichology 2017;9(01):14-18

84 Puig CJ, Reese R, Peters M. Double-blind, placebo-controlled pilot study on the use of platelet-rich plasma in women with female androgenetic alopecia. Dermatol Surg 2016;42(11):1243-1247

85 Singh SK, Kumar V, Rai T. Comparison of efficacy of platelet-rich plasma therapy with or without topical $5 \%$ minoxidil in male-type baldness: A randomized, double-blind placebo control trial. Indian J Dermatol Venereol Leprol 2020;86(02):150-157

86 Verma K, Tegta GR, Verma G, Gupta M, Negi A, Sharma R. A study to compare the efficacy of platelet-rich plasma and minoxidil therapy for the treatment of androgenetic alopecia. Int J Trichology 2019;11(02):68-79

87 Giordano S, Romeo M, Lankinen P. Platelet-rich plasma for androgenetic alopecia: Does it work? Evidence from meta analysis. J Cosmet Dermatol 2017;16(03):374-381

88 Gupta AK, Cole J, Deutsch DP, et al. Platelet-rich plasma as a treatment for androgenetic alopecia. Dermatol Surg 2019;45(10): 1262-1273

89 Vats G, Sonare D, Kachhawa D, Agrawal A, Jain V, Kataria R. A comparative study of the efficacy of platelet rich plasma, $10 \%$ minoxidil and microneedling in patients of androgenetic alopecia. WJPMR 2017;3(06):131-137

90 Kanti V, Messenger A, Dobos G, et al. Evidence-based (S3) guideline for the treatment of androgenetic alopecia in women and in men short version. J Eur Acad Dermatol Venereol 2018;32(01):11-22

91 Goh C. The need for evidence-based aesthetic dermatology practice. J Cutan Aesthet Surg 2009;2(02):65-71 